\title{
Penerapan Model Pembelajaran Probing Prompting Terhadap Kemampuan Pemahaman Konsep Matematika Siswa
}

\author{
Eka Rosdianwinata ${ }^{1}$, Muhammad Ridwan ${ }^{2}$ \\ 1,2 Program Studi Pendidikan Matematika Universitas Mathla'ul Anwar Banten
}

\begin{tabular}{l} 
ARTICLE INFO \\
\hline Article History: \\
Received 02.02.2018 \\
Received in revised \\
form 05.03.2018 \\
Accepted 30.03.2018 \\
Available online \\
20.04.2018
\end{tabular}

20.04.2018

\begin{abstract}
This study aims to determine the ability of understanding the Probing Prompting grade VIII MTs MA Cikaliung model. The research method used posttest-only nonequivalent control group design. Based on the results of hypothesis testing obtained $t$ count $=0.883$ and ttable $=-1.672$ with significance level $\alpha=0.05$. The words $\mathrm{H} 0$ and $\mathrm{H} 1$ are rejected, things that require an understanding of mathematical concepts capable of digging better than others.
\end{abstract}

Keywords:

Mathematical Concept, Probing Prompting.

DOI: $10.30653 / 003.201841 .46$

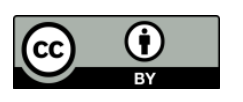

This is an open access article distributed under the terms of the Creative Commons Attribution 4.0 International License, which permits unrestricted use, distribution, and reproduction in any medium, provided the original work is properly cited. @ 2018 Eka Rosdianwinata, Muhammad Ridwan.

\section{PENDAHULUAN}

Pendidikan adalah usaha sadar dan terencana untuk mewujudkan suasana belajar dan proses pembelajaran agar siswa secara aktif mengembangkan potensi dirinya untuk memiliki kekuatan spiritual, pengendalian diri, kepribadian, kecerdasan, akhlak mulia, serta keterampilan yang diperlukan dirinya, masyarakat, bangsa dan Negara menurut Suparlan (Mustika \& Buana, 2017). Untuk mencapai tujuan pendidikan maka siswa harus diarahkan dengan proses pembelajaran yang menyenangkan terutama dalam proses pembelajaran matematika.

Mata pelajaran matematika diberikan kepada semua peserta didik untuk membekali mereka dengan kemampuan berpikir logis, analitis, sistematis, kritis, dan kreatif, koneksi matematika, serta kemampuan bekerjasama. Mata pelajaran matematika dapat mengasah otak, siswa tidak hanya sekedar menghapal rumus-rumus matematika saja, tetapi juga harus dapat menggunakan konsep ilmu matematika untuk memecahkan permasalahan yang ada disekitar kehidupannya. Penyajian permasalahan yang berhubungan dengan kehidupan sehari-hari dalam mata pelajaran matematika diharapkan dapat membawa siswa untuk mengerti manfaat dari ilmu yang mereka pelajari.

Matematika sebagai salah satu bidang studi yang wajib diajarkan disekolah mulai dari tingkat sekolah dasar sampai perguruan tinggi. Fakta bahwa matematika merupakan ilmu yang memegang peranan penting dan mesti dikuasai oleh setiap orang, tetapi pada kenyataannya banyak orang khususnya siswa tidak menyenangi pelajaran matematika. Kondisi yang demikian itu menuntut seorang guru matematika perlu mencari terobosan baru dalam mengajarkan pelajaran matematika

${ }^{1}$ Corresponding author's address: Program Studi Pendidikan Matematika, FKIP of Universitas Mathla'ul Anwar Banten, Indonesia e-mail: rd.winata@unmabanten.ac.id 
agar pelajaran yang diberikan lebih menarik dan menyenangkan. Keberhasilan pembelajaran matematika dapat diukur dari keberhasilan siswa yang mengikuti kegiatan pembelajaran tersebut. Keberhasilan tersebut dapat dilihat dari tingkat pemahaman, penguasaan materi, serta prestasi belajar siswa.

Sekolah Menengah Pertama (SMP) merupakan jenjang pendidikan dasar yang bertujuan untuk meletakkan dasar kecerdasan, pengetahuan, kepribadian, akhlak mulia, serta keterampilan untuk hidup mandiri dan mengikuti pendidikan lebih lanjut. Pembelajaran matematika di SMP memiliki tujuan agar siswa memiliki kemampuan memahami konsep matematika, menjelaskan keterkaitan antar konsep, dan mengaplikasikan konsep atau algoritma secara luwes, akurat, efisien dan tepat dalam pemecahan masalah. Pembelajaran matematika pada dasarnya adalah suatu proses belajar mengajar yang dibangun oleh guru untuk mengembangkan kreativitas berpikir siswa, serta dapat mengkonstruksi pengetahuan baru sebagai upaya meningkatkan penguasa yang baik terhadap materi matematika (Wardhani, 2008; Susanto, 2015) dalam (Siti mawaddah, 2016).

Pemahaman konsep merupakan pengertian yang benar tentang suatu rancangan atau ide abstrak. Oleh sebab itu para peserta didik dituntut untuk memiliki pola kemampuan berpikir yang luas sehingga dapat terarah dan dapat menghasilkan suatu tujuan yang hendak dicapai.

Faktor-faktor yang dapat meningkatkan kemampuan pemahaman konsep, antara lain adalah kemampuan mencari informasi yang relevan. Siswa harus dapat membedakan informasi yang relevan dan yang tidak relevan terhadap masalah yang dihadapinya. Faktor-faktor yang berpengaruh terhadap kemampuan siswa pemahaman konsep dalam matematika adalah kemampuan memahami ruang lingkup masalah dan mencari informasi yang relevan, kemampuan dalam memilih pendekatan atau strategi masalah, kemampuan berpikir dan bernalar siswa, sikap siswa dan latihan-latihan.

MTs Mathla'ul Anwar Cikaliung adalah salah satu sekolah swasta yang ada di wilayah pandeglang. Di sekolah ini siswa masih kurang dalam minat belajar matematika, sehingga keaktifan siswa di dalam kelas juga masih kurang terlihat. Sedangkan kemampuan pemahaman konsep matematika siswa MTs Mathla'ul Anwar Cikaliung masih tergolong rendah ini terlihat dari yang terjadi pada saat pembelajaran matematika berlangsung seperti kesulitannya siswa dalam mengulang dan menguasai konsep matematika, kurang mampunya siswa dalam Mengklasifikasi obyek-obyek menurut sifat-sifat tertentu (sesuai dengan konsepnya). Serta kurang mampunya siswa dalam memberikan contoh dari suatu konsep matematika.

Untuk mengantisipasi masalah tersebut agar tidak berkelanjutan dan untuk meningkatkan hasil belajar siswa pada mata pelajaran matematika, maka seorang guru berusaha menyusun dan menerapkan berbagai cara yang bervariasi salah satu cara agar siswa bisa lebih interaktif yaitu melalui model pembelajaran probing prompting.

Dengan model tersebut diharapkan dapat membuat siswa menikmati proses belajar matematika di sekolah. Pada akhirnya dapat memberikan pengaruh terhadap kemampuan pemahaman konsep matematika siswa dalam proses belajar yang dapat mengarahkan siswa ke suasana pembelajaran yang efektif dan menyenangkan yang dapat memberikan pengaruh positif terhadap siswa. Penerapan model pembelajaran ini diharapkan mampu menciptakan suatu pelajaran yang efektif yang mampu meningkatkan kreativitas serta pemahaman siswa terhadap suatu pelajaran. Untuk mengetahui apakah kegiatan pembelajaran di sekolah sesuai yang diharapkan, peneliti melakukan penelitian di MTs Mathla'ul Anwar Cikaliung.

Berdasarkan uraian diatas maka rumusan masalah adalah: Apakah kemampuan pemahaman konsep matematika siswa dengan pembelajaran probing prompting lebih baik daripada kemampuan pemahaman konsep siswa dengan pembelajaran konvensional siswa kelas VIII MTs MA Cikaliung. Adapun rumusan masalah yang telah dikemukakan diatas, maka tujuan penelitian ini adalah: Tujuan penelitian ini adalah untuk mengetahui kemampuan pemahaman konsep matematika siswa dengan penerapan model pembelajaran Probing Prompting lebih baik daripada kemampuan pemahaman konsep matematika siswa dengan pembelajaran konvensional siswa kelas VIII MTs MA Cikaliung. 
Model pembelajaran probing prompting adalah pembelajaran dengan cara guru menyajikan serangkaian pertanyaan yang sifatnya menuntun dan menggali sehingga terjadi proses berpikir yang mengaitkan pengetahuan tiap siswa dan pengalamannya dengan pengetahuan baru yang sedang dipelajari. Selanjutnya, siswa mengonstruksi konsep-prinsip dan aturan menjadi pengetahuan baru, dengan demikian pengetahuan baru tidak diberitahukan menurut Suherman (Mokhamad Ridwan Yudhanegara, 2015).

Adapun Langkah-langkah pembelajaran probing-prompting dijabarkan melalui tujuh tahapan teknik probing yang dikembangkan dengan prompting adalah sebagai berikut:

1) Guru menghadapkan siswa pada situasi, misalkan dengan memperhatikan gambar, atau situasi lainnya yang mengandung permasalahan.

2) Memberikan kesempatan kepada siswa untuk merumuskan jawaban.

3) Guru mengajukan persoalan kepada siswa yang sesuai dengan tujuan pembelajaran.

4) Memberikan kesempatan pada siswa untuk merumuskan jawaban.

5) Meminta salah satu siswa untuk menjawab pertanyaan.

6) Jika jawabannya tepat maka guru meminta tanggapan kepada siswa lain tentang jawaban tersebut untuk meyakinkan, bahwa seluruh siswa terlibat dalam kegiatan yang sedang berlangsung. Namun jika siswa tersebut mengalami kesulitan menjawab dalam hal ini jawaban yang diberikan kurang tepat, tidak tepat, atau diam, maka guru mengajukan pertanyaan lain yang jawabannya merupakan petunjuk jalan penyelesaian jawaban. Lalu, dilanjutkan dengan pertanyaan yang menuntut siswa berpikir pada tingkat yang lebih tinggi, sampai dapat menjawab pertanyaan sesuai dengan kompetensi dasar atau indikator. Pertanyaan yang dilakukan pada langkah keenam ini sebaiknya diajukan kepada beberapa siswa yang berbeda agar seluruh siswa terlibat dalam seluruh kegiatan probing prompting.

7) Guru mengajukan pertanyaan akhir kepada siswa yang berbeda untuk lebih memastikan bahwa indikator yang dicapai telah dipahami oleh siswa.

Hipotesis dalam penelitian ini adalah kemampuan pemahaman konsep matematika siswa dengan penerapan model pembelajaran probing prompting lebih baik daripada kemampuan pemahaman konsep matematika siswa dengan pembelajaran konvensional siswa kelas VIII MTs MA Cikaliung.

\section{METODE}

Berdasarkan permasalahan dan tujuan yang ingin dicapai penelitian ini menggunakan pendekatan kuantitatif dalam bentuk Quasi-Experimental. Jenis penelitian ini digunakan karena tidak memungkinkan untuk mengontrol keseluruhan variabel yang ada dalam penelitian. Metode penelitian ini menggunakan metode eksperimen yaitu kelompok eksperimen yang diberi perlakuan dengan menggunakan model pembelajaran probing prompting dan kelompok kontrol dengan menerapkan pembelajaran secara konvensional.

Adapun desain penelitian ini menggunakan The Nonequivalent posttest-only control group design dan dapat digambarkan sebagai berikut:

\begin{tabular}{|lcc|}
\hline Sampel & Variabel & Postest \\
Eksperimen & $\mathrm{X}$ & $\mathrm{O}$ \\
Kontrol & & $\mathrm{O}$ \\
\hline
\end{tabular}

Keterangan:

$X$ : Perlakuan/ Treatment yang diberikan (Variabel Independen)

$\mathrm{O}:$ Postest (variabel dependen yang diobservasi)

Rancangan ini diterapkan pada situasi belajar yang berbeda yakni dengan pembelajaran probing prompting pada kelas eksperimen dan pembelajaran konvensional pada kelas kontrol. Penelitian ini dilaksanakan dalam tiga hari disalah satu sekolah di daerah kabupaten pandeglang atau lebih tepatnya MTs Mathla'ul Anwar Cikaliung. Setelah melakukan pengacakan maka peneliti mendapatkan dua kelas yang diteliti yaitu kelas VIII A dan VIII B. Dari kedua kelas tersebut peneliti 
melakukan pengundian dalam rangka untuk menetapkan kelas yang dijadikan kelas eksperimen atau kontrol. Setelah melakukan pengundian maka kelas yang terpilih menjadi kelas eksperimen adalah kelas VIII B dan kelas kontrol adalah kelas VIII A.

Penelitian ini dilaksanakan di MTs Mathla'ul Anwar Cikaliung di kelas VIII, dengan kelas VIII A berjumlah 30 siswa sebagai kelas kontrol dan kelas VIII B berjumlah 30 siswa sebagai kelas eksperimen. Jadi peserta yang mengikuti tes akhir berjumlah 60 orang siswa. Setelah diberikan perlakuan yang berbeda, kemudian kedua kelas diberi posttest untuk mengukur kemampuan pemamahaman konsep. Hasil posttest ini dijadikan data untuk menguji hipotesis dalam penelitian. Sebelum hipotesis dilakuan terlebih dahulu dilakukan uji normalitas dan homogenitas.

\section{HASIL DAN PEMBAHASAN}

Pengujian normalitas ini dengan menggunakan uji chi kuadrat, Uji normalitas bertujuan untuk mengetahui apakah data berasal dari sampel berdistribusi normal atau tidak. Uji normalitas pada kelas sampel dengan $\alpha=0,05$ dapat dilihat pada Tabel 1 .

Tabel 1. Hasil Uji Normalitas Data Kemampuan Pemahaman Konsep Matematika

\begin{tabular}{llllc}
\hline Kelas & $\mathrm{N}$ & Chi Kuadrat hitung & Chi kuadrat tabel & Ket \\
\hline Eksperimen & 30 & 7,81 & \multirow{2}{*}{11,1} & Normal \\
\hline Kontrol & 30 & 9,69 & & \\
\hline
\end{tabular}

Selain data berasal dari sampel berdistribusi normal, harus diperhatikan juga apakah kedua sampel homogen atau tidak. Maka dilakukan uji homogenitas dengan $\alpha=0,05$ dengan $\mathrm{dk}=60$. Hasil uji homogenitas dapat dilihat pada Tabel 2.

Tabel 2. Hasil Analisis Homogenitas Data Kemampuan Pemahaman Konsep

\begin{tabular}{lccccc}
\hline Kelas & $\mathrm{N}$ & Varians & Fhitung & Ftabel & Ket \\
\cline { 1 - 3 } Eksperimen & 30 & 86,12 & \multirow{2}{*}{1,78} & \multirow{2}{*}{1,85} & \multirow{2}{*}{ Homogen } \\
\hline Control & 30 & 108,37 & & & \\
\hline
\end{tabular}

Pengujian hipotesis digunakan untuk mengetahui hasil tes kemampuan pemahaman konsep siswa yang dikenai dengan model pembelajaran probing prompting daripada kemampuan pemahaman konsep siswa yang dikenai model pembelajaran konvensional pada materi peluang di kelas VIII MTs Mathla'ul Anwar Cikaliung. Hasil uji hipotesis dapat dilihat dari tabei 3.

Tabel 3. Hasil Uji Hipotesis Data Pemahaman Konsep Matematika Siswa

\begin{tabular}{lcccccc}
\hline Kelas & $\mathrm{N}$ & Rerata & $\mathrm{S}$ & $\mathrm{S}^{2}$ & thitung & tabel \\
\cline { 1 - 5 } Eksperimen & 30 & 66,3 & 9,28 & 86,12 & \multirow{2}{*}{0.883} & \multirow{2}{*}{1,672} \\
\hline Control & 30 & 55,9 & 10,41 & 108,37 & & \\
\hline
\end{tabular}

Dari Tabel di atas diperoleh hasil perhitungan uji hipotesis diperoleh $t_{\text {hitung }}=0,883$ dengan $\mathrm{dk}=$ $(30+30-2)=58$ dan taraf nyata $5 \%$ maka diperoleh $t_{\text {tabel }}=-1,672$. Karena $t_{\text {hitung }}$ berada pada daerah penolakan $\mathrm{H}_{1}$, artinya rata-rata kemampuan pemahaman konsep matematika kelas eksperimen lebih baik daripada rata-rata kemampuan pemahaman konsep matematika kelas kontrol atau hasil tes kemampuan pemahaman konsep matematika siswa yang dikenai model probing prompting lebih baik daripada hasil tes kemampuan pemahaman konsep matematika siswa yang dikenai pembelajaran konvensional pada materi Peluang di kelas VIII MTs Mathla'ul Anwar Cikaliung. Secara umum hasil yang diperoleh melalui penelitian ini menunjukan bahwa penerapan model pembelajaran Probing Prompting dapat memberi pengaruh positif terhadap kemampuan pemahaman konsep matematika siswa. Hal ini didasarkan pada perbedaan rata-rata skor kemampuan pemahaman konsep matematika siswa kelas eksperimen lebih baik daripada kelas kontrol. Dari hasil tersebut dapat disimpulkan bahwa rata-rata kemampuan pemahaman konsep matematika siswa pada kelas eksperimen lebih baik daripada rata-rata kemampuan pemecahan masalah matematika siswa kelas kontrol. 
Hasil tes kemampuan pemahaman konsep matematika kedua kelas dapat dilihat pada tabel berikut: Tabel 4. Hasil Tes Kemampuan Pemahaman Konsep Matematika

\begin{tabular}{lccccc}
\hline \multirow{2}{*}{ Kelas } & \multirow{2}{*}{$\mathrm{N}$} & \multicolumn{5}{c}{ No soal } \\
\cline { 3 - 6 } & & 1 & 2 & 3 & 4 \\
\hline Eksperimen & 30 & 30 & 20 & 5 & 0 \\
\hline Control & 30 & 30 & 15 & 3 & 0 \\
\hline
\end{tabular}

Dari Tabel 4 dapat diketahui hasil tes kemampuan pemahaman konsep matematika. Jumlah siswa kelas eksperimen yang menjawab benar soal nomor 1 adalah 30 siswa, dan yang menjawab benar soal nomor 2 adalah 20 siswa, dan yang menjawab benar soal nomor 3 adalah 5 orang, sedangkan nomor 4 tidak ada yang menjawab karena lembar jawaban kosong karena waktu pengerjaan atau jam pelajaran sudah habis. Dan dari table diatas juga dapat kita ketahui hasil tes kemampuan pemahaman konsep matematika kelas kontrol. Jumlah siswa kelas kontrol yang menjawab benar soal nomor 1 adalah 30 siswa, sedangkan yang menjawab benar soal nomor 2 adalah 15 siswa, dan yang menjawab benar soal nomor 3 adalah 3 siswa, dan yang menjawab benar soal nomor 4 tidak ada yang menjawab karena keterbatasan waktu.

Tabel 5. Perbandingan Nilai Tes Siswa Kelas Eksperimen dan Kontrol

\begin{tabular}{lcccccc}
\hline Kelas & $\mathrm{N}$ & Rerata & $\mathrm{S}$ & $\mathrm{S}^{2}$ & Min & Max \\
\hline Eksperimen & 30 & 66,3 & 9,28 & 86,12 & 45 & 80 \\
\hline Control & 30 & 55,9 & 10,41 & 108,37 & 40 & 75 \\
\hline
\end{tabular}

Dari Tabel 5 terlihat nilai rata- rata kelas eksperimen adalah 66,3 dan nilai rata-rata kelas kontrol adalah 55,9, sedangkan standar deviasi kelas eksperimen adalah 9,28 dan nilai standar deviasi kelas kontrol adalah 10,41, sedangkan varians kelas eksperimen adalah 86,12 dan varians kelas kontrol adalah 108,37. Sedangkan nilai terendah kelas eksperimen adalah 45 dan nilai terendah kelas kontrol adalah 40. Sedangkan nilai tertinggi kelas eksperimen adalah 80 dan nilai tertinggi kelas kontrol adalah 75. Ini menunjukkan kelas eksperimen lebih baik daripada kelas kontrol.

Dalam pengujian hipotesis, hasil perhitungan uji hipotesis diperoleh $t_{\text {hitung }}=0,883$ dengan $\mathrm{dk}=$ $(30+30-2)=58$ dan taraf nyata $5 \%$ maka diperoleh $t_{\text {tabel }}=-1,672$. Karena $t_{\text {hitung }}$ berada pada daerah penolakan $\mathrm{H}_{1}$, artinya rata-rata kemampuan pemahaman konsep matematika kelas eksperimen lebih baik daripada rata-rata kemampuan pemahaman konsep matematika kelas kontrol atau hasil tes kemampuan pemahaman konsep matematika siswa yang dikenai pembelajaran probing prompting lebih baik daripada hasil tes kemampuan pemahaman konsep matematika siswa yang dikenai pembelajaran konvensional pada materi Peluang di kelas VIII MTs Mathla'ul Anwar Cikaliung.

\section{SIMPULAN}

Berdasarkan hasil penelitian dan pembahasan diperoleh kesimpulan bahwa rata- rata kemampuan pemahaman konsep matematika siswa yang memperoleh metode pembelajaran probing prompting lebih baik daripada rata-rata kemampuan pemahaman konsep matematika siswa yang memperoleh metode pembelajaran konvensional pada sisa kelas VIII MTs MA Cikaliung.

\section{REFERENSI}

Antika, R. R. (2014). Proses Pembelajaran Berbasis Student Centered Learning (Studi Deskriptif di Sekolah Menengah Pertama Islam Baitul ‘Izzah, Nganjuk). Jurnal BioKultur, 3(1), 251-265.

Budiyanto, M. A. K. (2016). SINTAKS 45 Model Pembelajaran dalam Student Centered Learning (SCL). Malang: UMM Press. 
Lestari, K. E., \& Yudhanegara, M. R. (201)5. Penelitian Pendidikan Matematika. Bandung: Refika Aditama.

Mawaddah, S., \& Maryanti, R. (2016). Kemampuan Pemahaman Konsep Matematis Siswa SMP dalam Pembelajaran Menggunakan Model Penemuan Terbimbing (Discovery Learning). EDUMAT, 4(1), 76-85.

Mustika, H., \& Buana, L. (2017). Penerapan model pembelajaran probing promptıng terhadap kemampuan pemecahan masalah matematıka siswa. MES (Journal of Mathematics Education and Science), 2(2).,30-37.

Riduwan. (2014). Dasar-Dasar Statistika. Bandung: Alfabeta.

Sugiyono. (2015). Metode Penelitian Pendidikan: Bandung: Alfabeta. 